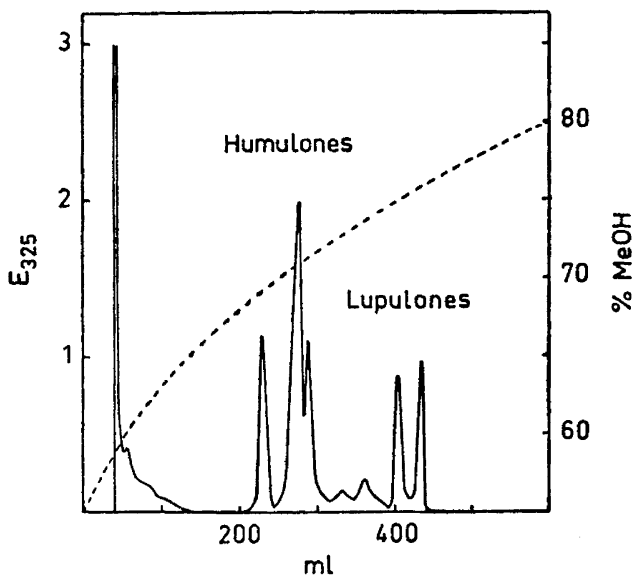

Fig. 1. Gradient elution analysis of humulones and lupulones from Hallertau hops. Column $800 \times 8 \mathrm{~mm}$.

in one single operation by means of gradient elution. If the analysis of the eluate is performed spectrophotometrically at $325 \mathrm{~m} \mu$, where the contributions from other hop substances is small, a solvent extract of hops can be used without purification. Fig. 1 shows the result of an analysis of the humulone and lupulone groups of Hallertau hops. The concentration gradient of the eluant was accomplished by letting $90 \%(\mathrm{w} / \mathrm{w})$ methanol flow into a constant volume mixing chamber loaded with $55 \%(w / w)$ methanol, the effluent of which was fed to the column. The resolution was satisfactory but somewhat less complete than with normal elution. Thus lupulone and adlupulone were not separated.

In other experiments it has been possible to vary the methanol concentration over still wider ranges. Carbon tetrachloride extracts of hops have been shown to be very heterogeneous mixtures contain. ing substances which may be eluted at methanol percentages varying from 0 to $85 \%$ or still higher.

The collection of eluate fractions from a chromatographic column and the determination of the ultraviolet absorption of each fraction are inherently subject to systematic errors, which may be of a considerable magnitude, especially when working with substances which are unstable to air. The column effluent was therefore passed through a $5 \mathrm{~mm}$ absorption cell in a Hilger Uvispek spectrophotometer and the optical density at 280 or $325 \mathrm{~m} \mu$ recorded automatically by a Brown recorder.

1. Spetsig, L. O, and Steninger, Maj, J. Inst. Brewing 62 (1956) 333.

Received January 14, 1957.

\section{On the Production of Magnetic Centres in Glycine by X-Rays}

\author{
A. EHRENBERG, L. EHRENBERG \\ and K. G. ZIMMER
}

Biochemical Department, Nobel Medical Institute; Institute for Organic Chemistry and Biochemistry, University; and Genetics Department, Forest Research Institute, Stockholm, Sweden

The demonstration of the production of magnetic centres in a variety of chemicals by ionizing radiation might well lead to a better understanding of the mechanisms by which a relatively small amount of energy absorbed in the form of radiation causes marked biological effects ${ }^{1-4}$. The paramagnetic resonance spectra obtained have been tentatively explained by assuming that organic free radicals constitute the magnetic centres ${ }^{5-8}$. These results are of great interest to radiation biology when considered in relation to other evidence concerning aftereffects of irra. diation and protection against radiation damage ${ }^{2}$. We thought it worth while to try and obtain data in order to evaluate, more quantitatively, the importance of the earlier observations for radiation biology. As a first step we investigated the relation between the dose of radiation administered and the number of magnetic centres produced in an amino acid, glycine.

For irradiation we used $\mathrm{X}$-rays produced at $175 \mathrm{kV}$ and filtered by $2 \mathrm{~mm}$ of aluminium (about $800 \mathrm{r} \cdot \mathrm{min}^{-1}$ ). The dose was measured during the irradiation by means of a wavelength independent thimble chamber connected to a valve electrometer and integrating counter (Duplex-Dosemeter) carefully calibrated in Roentgens. The glycine, in amounts of about $150 \mathrm{mg}$, in the form of small crystals, was irradiated in evacuated and sealed quartz tubes, which were only half-filled. This en-

Acta Chem. Scand. 11 (1957) No. 1 


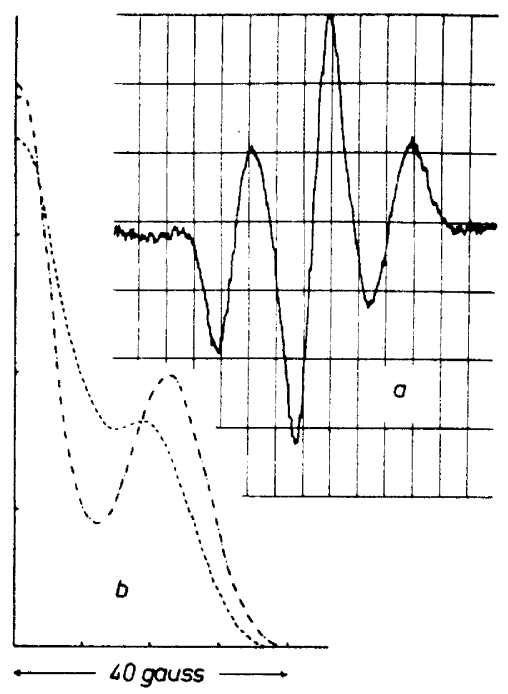

Fig. 1 a. Derivative of paramagnetic resonance spectrum of glycine, as recorded immediately after irradiation.

$b$. Paramagnetic resonance spectrum of glycine, -... immediately and ............... 12 days after irradiation (integrated derivative curves).

abled one half of the tubes to be shielded from irradiation, and, after shaking the glycine into the unirradiated part of the tube, the measurement of paramagnetic resonance was conducted excluding completely the well known effects of radiation on quartz. The unirradiated quartz did not show any detectable signal. The spectrometer ${ }^{10}$ used contained a simple microwave bridge operating at a frequency of $9400 \mathrm{Mc}$. The signal reflected from the cavity could be recorded as an absorption curve on an oscillograph or as a derivative curve by means of a pen recorder. Irradiation and magnetic measurements were conducted at room temperature.

The spectra observed immediately after the irradiation (Fig. 1 a) showed a central perk at a g-value of $2.004( \pm 0.001)$ and two satellites at \pm 22.4 gauss. On keeping the material in vacuo and repeating the measurements the shape of the spectrum was found to change slowly (Fig. 1 b), though the area under the absorption curves remained essentially constant. This may be taken to indicate a constant num. ber of magnetic centres. The decay, if any, is less than $1 \%$ per day at about $20^{\circ} \mathrm{C}$.

Spectra of identical shape could be recorded in the range from $2 \mathrm{kr}$ to $350 \mathrm{kr}$, thus including much of the region of biological interest. Since the shape of the curves is independent of dosage, the linear rise in amplitude with dosage, shown in Fig. 2, indicates a corresponding increase in the number of magnetic centres.

Intensity, shape, and time dependence of the recorded spectra were not changed by the presence of air, neither during nor after irradiation, contrasting with results published for some other substances ${ }^{5}$.

By comparing the areas under the absorption spectra of irradiated glycine and of a known amount of free radicals (diphenylpicryl hydrazyl) a rough estimate of the concentration of free radicals produced per unit dose in glycine could be obtained. The yield was found to be of the order of magnitude of 1 radical per $10 \mathrm{eV}$ of radiation energy absorbed, i. e., much higher than the values reported for plastics ${ }^{11}$.

Another series of experiments was conducted with living material. Embryos cut from resting barley seeds yielded a resonance peak at a g-value characteristic of free radicals, when irradiated in air or in nitrogen. A more detailed account of these studies will appear elsewhere.

Acknowledgements. This work has been supported financially by the Swedish Natural Science Research Council, the Magnus Bergvall Foundation and the Knut and Alice Wallen.

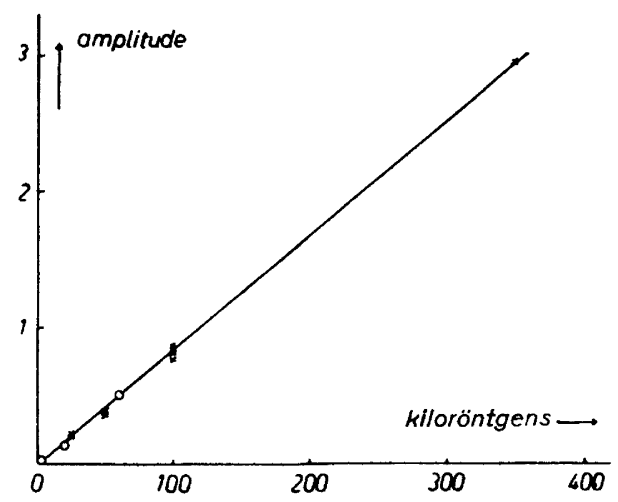

Fig. 2. Derivative amplitude (arbitrary units) of the paramagnetic absorption curve of glycine as a function of dose of irradiation by X-rays. $X$ and $O$ : two different series of experiments. 
berg Foundation. Thanks are also due to Professor M. Siegbahn, Head of the Nobel Institute of Physics, for permission to use equipment of his institute. One of us (K.G.Z.) also wants to express his gratitude to the MaxPlanck-Gesellschaft, Göttingen, for a maintenance and travelling grant.

1. Timoféeff-Ressovsky, N. W. and Zimmer, K. G. Das Trefferprinzip in der Biologie, Leipzig 1947.

2. Zimmer, K. G. Acta Radiol. 46 (1956) 595.

3. Alper, T. Radiation Research 5 (1956) 573.

4. Gray, L. H. Radiation Research 1 (1954) 189.

5. Gordy, W., Ard, W. B. and Shields, H. Proc. Natl. Acad. Sci. U.S. 41 (1955) 983.

6. Gordy, W., Ard, W. B. and Shields, H. Proc. Natl. Acad. Sci. U.S. 41 (1955) 996.

7. Luck, C. F. and Gordy, W. J. Am. Chem. Soc. 78 (1956) 3240.

8. Gordy, W. and McCormick, C. G. J. Am. Chem. Soc. 78 (1956) 3243.

9. Ehrenberg, L. and Zimmer, K. G. Iereditas 42 (1956) 515.

10. Ehrenberg, A. and Hellström, B. In preparation.

11. Schneider, E. E. Discussions Faraday Soc. No. 19 (1955) 158.

Received January 15, 1957.

\section{The Reduction of Plutonium by Tetravalent Uranium}

\author{
J A N R Y D B E R G
}

\section{Research Institute of National Defence,} Dept. 1, Sundbyberg 4, Sweden

Tn the search for substances to reduce Ismoll amounts of plutonium of higher oxidation states to $\mathrm{Pu}(\mathrm{III})$ in the presence of large amounts of U(VI), U(IV) has been tested under a number of various conditions. The use of $\mathrm{U}(\mathrm{IV})$ for reducing plutonium does not seem not to have been described previously ${ }^{1}$.

Tetravalent uranium at concentrations $\geq 0.01 \mathrm{M}$ has been found to be stable in solutions of most acids for weeks or months if air is excluded. However, the stability in $\mathrm{HNO}_{3}$ is poor, but increases with the U(IV) concentration. Maximum stability in $\mathrm{HNO}_{3}$ seems to be obtained around $1 \mathrm{M}$ $\mathrm{HNO}_{3}$, where about $50 \%$ of originally $0.1 \mathrm{M} U(\mathrm{IV})$ is reduced in a little more than an hour at room temperature. Thus U(IV) can be used as a reducing agent even in $\mathrm{HNO}_{3}$ solutions, provided the time of the experiments does not much exceed an hour.

In $1 \mathrm{M} \mathrm{HNO}, \mathrm{Pu}(\mathrm{IV})$ and $\mathrm{Pu}(\mathrm{VI})$ are quantitatively $(>99 \%)$ reduced to $\mathrm{Pu}(\mathrm{III})$ by $0.1 \mathrm{M} U(\mathrm{IV})$ within $5 \mathrm{~min}$ at room temperature. This effect can theoretically be used for separating uranium from plutonium in liquid-liquid extractions, if U(VI), U(IV), Pu(VI) and Pu(IV) prefer the organic phase and $\mathrm{Pu}(\mathrm{III})$ only prefers the aqueous phase ${ }^{2}$. The practical usefulness of this was tested in two sets of experiments.

In the first set of experiments two solutions were prepared. The organic solution consisted of methyl isobutyl ketone, which was $1.0 \mathrm{M}$ in $\mathrm{HNO}_{3}$ and contained $\mathrm{Pu}(\mathrm{IV})$ and $\mathrm{Pu}(\mathrm{VI})$; the aqueous solution was $0.7 \mathrm{M}$ in $\mathrm{HNO}_{3}, 3 \mathrm{M}$ in $\mathrm{Ca}\left(\mathrm{NO}_{3}\right)_{2}$ and contained a reductant. When these two phases are equilibrated with each other, the distribution ratio of the metals between the organic and the aqueous phases is for $\mathrm{U}(\mathrm{VI}) \mathrm{12}, \mathrm{U}(\mathrm{IV}) \sim 10, \mathrm{Pu}(\mathrm{VI}) \mathrm{13}, \mathrm{Pu}(\mathrm{IV})$ 9 , and $\mathrm{Pu}(\mathrm{III}) \lesssim 0.001^{3}$; of these species thus only $\mathrm{Pu}(\widetilde{I I I})$ prefers the aqueous phase, and can easily be separated from the other metal ions. After the two phases had been shaken together, the amount of reduced plutonium (i.e. $\mathrm{Pu}$ (III)) was determined. Some of the results obtained with different reductants are given in the table for $5 \mathrm{~min}$ equilibration time.

$$
\begin{array}{cc} 
& \% \\
\text { Reducing agent } & \mathrm{Pu} \\
& \text { reduced }
\end{array}
$$$$
0.05 \mathrm{M} \mathrm{NH}_{2} \mathrm{OH} \cdot \mathrm{HCl}+0.005 \mathrm{M} \mathrm{Fe}^{2}+65 \pm 8
$$$$
0.05 \mathrm{M} \mathrm{H}_{4} \mathrm{NOSO}_{2} \mathrm{NH}_{2}+0.005 \mathrm{M} \mathrm{Fe}+65 \pm 10
$$$$
0.05 \mathrm{M} \mathrm{U}^{4}+\text { in air } \quad 70 \pm 10
$$$$
0.05 \mathrm{M} \mathrm{U}^{+} \text {in } \mathrm{N}_{2} \quad 95 \pm 3
$$

It is seen that U(IV) is equally or more effective than iron(II) plus hydroxylamine or sulfamate.

In the second set of experiments, the organic phase contained $\mathrm{Pu}(\mathrm{IV})$ as the uncharged TTA complex in 0.1 M TTA (thenoyltrifluoroacetone) in benzene, while the aqueous phase was $0.33 \mathrm{M}$ in $\mathrm{HClO}_{4}$ and contained U(IV). For $0.010 \mathrm{M} \mathrm{U}(\mathrm{IV})$, $14 \% \mathrm{Pu}$ had been reduced in $30 \mathrm{~min}$, and $60 \%$ in $20 \mathrm{~h}$.

These experiments show the usefulness of $U(I V)$ as a reducing agent for plutonium, either in aqueous solution or in two-phase 